\title{
An obligation to enhance?
}

\author{
Anton Vedder \\ KU Leuven Centre for IT and IP Law \\ Sint-Michielsstraat 6, bus 3443, 3000 LEUVEN, Belgium \\ Email: anton.vedder@kuleuven.be \\ Phone: +3216326923
}

Cite this article as: Vedder, A. Topoi (2017). https://doi.org/10.1007/s11245-017-9483-7

Publisher: Springer Netherlands Print ISSN 0167-7411 Online ISSN 1572-8749

\begin{abstract}
This article discusses some characteristics of possible obligations to enhance. Obligations to enhance can exist in the absence of good moral reasons. The existence of such obligations therefore need not be morally desirable. If obligation and duty are considered as synonyms, the enhancement involved must be morally desirable in some respect. Since enhancers and enhanced can, but need not coincide, advertency is appropriate regarding the question who exactly is addressed by an obligation or a duty to enhance: the person on whom the enhancing treatment is performed, or the controller or the operator of the enhancement? Especially, the position of the operator is easily overlooked. Finally, the exact functionality of the specific enhancement, is all-important, not only for the acceptability of a specific form of enhancement, but also for its chances of success for becoming a duty or morally obligatory. Moral enhancement is a controversial and questionable candidate for becoming morally obligatory.
\end{abstract}

Key words: enhancement, cognitive enhancement, moral enhancement, obligation, ethics, law.

\section{Introduction}

Most debates on human enhancement focus on definitional issues regarding enhancement and therapy and on the moral acceptability of (specific types of) enhancement. Suppose that there would be forms of human enhancement that are not only morally acceptable, but even morally desirable - could there be even an obligation or obligations to enhance? A few years ago, a colleague and I published an article in which we discussed the use of Transcranial Magnetic Stimulation (TMS) for the purpose of eyewitness enhancement (Vedder and Klaming 2010). We analyzed a whole set of arguments for and against cognitive human 
enhancement in general, and this specific application in particular. Although we were critical about the arguments against this use of TMS, we did not strongly advocate this form of enhancement for this particular purpose. We simply observed that if forms of cognitive enhancement would find their way into society, this might happen along the trajectory of being recognized as a contribution to the common good and we explained that TMS for witness enhancement might be considered to be such a contribution to the common good, provided that specific conditions would apply. Among the latter should certainly figure the presence of safeguards for the fairness and impartiality of the procedure and of course the proven efficacy of this type of enhancement. The article provoked extensive comments and quite a debate. Interestingly, not a majority but nonetheless a significant number of the people who responded read our article as a plea for obliging witnesses in a criminal procedure to undergo TMS. To us this came as a surprise. We thought we had done not much more than explain that thinking about the use of TMS in this context, provided that it would be effective, was not a bizarre idea and that if human enhancement were to be considered morally acceptable, then that might amongst others happen because some forms of enhancement would be considered to contribute to an important public interest.

Can there ever be obligations to enhance in societies such as ours? What would be the formal characteristics of such obligations? I understand these questions to be primarily conceptual and only secondarily empirical ones, meaning that the questions ask for the layers of the meanings of "obligation" and "enhancement" that may uncover some of the conditions to be fulfilled for an obligation or a plurality of obligations to enhance to exist. Of course, the empirical question could be answered in various ways: psychologically, sociologically, historically et cetera. All of the disciplinary perspectives mentioned would be relevant to the debate on human enhancement, if only to explore the vague and fluid borders between therapy and enhancement. My approach, however, will be more basic, mainly consisting of conceptual analysis. It will be a formal approach as I do not intend to make a substantial moral argument about the acceptability or even the desirability of moral enhancement. The analysis and its results may be of help for the moral assessment of various forms of enhancement, although I will mainly use a specific form of cognitive enhancement, i.e. TMS for purposes of improving memories, frequently as an example. It may also help to draw attention to the sheer possibility of the occurrence of non-moral or even immoral obligations to enhance in the absence of moral duties to enhance.

\section{Acceptability, duty or obligation?}

Moral acceptability of a type of actions refers primarily to the absence of (strong) moral or morally relevant reasons against a specific type of actions. Applying TMS voluntarily for memory enhancement, for example, does not imply any safety risks to the health of the person involved, nor does it entail a restriction on his or her autonomy or privacy or harm or offend any other person. If there would not be any other good moral reasons against this application, it could therefore be deemed morally acceptable. In order to become a moral duty there should be some additional beneficial effect for the person involved or for others or society as a whole resulting in a good moral reason in favor of undergoing TMS. In the example of TMS, the prevention of harm to others, e.g. through false accusations, or a 
contribution to the public interest that cannot be obtained without the application could be such advantages.

The notions of obligation and duty are often used interchangeably. Sometimes, however, they are used in specific distinct ways. For the purposes of this paper it might be useful to have a closer look at duties and obligations as distinct categories.

A duty is sometimes used to refer to a responsibility that a person has merely on the basis of a moral reason or of moral reasoning, moral considerations in general - regardless of any prior agreements, promises or regulatory frameworks. Persons that act as eyewitnesses in criminal procedures could have a duty to undergo TMS treatment, for instance. This could be the case when such treatment would be deemed desirable because it would improve relevant memories, increase the accuracy of evidence used and thus contribute to the public interest, and avoid that harm be done to specific persons who might be wrongly accused were the quality of the witness's memory not enhanced. Since duties of beneficence are mostly supposed not to require serious or disproportional harm to self, an additional condition for such a duty to exist would be that the TMS would not harm the witnesses involved. Finally, the existence of such a duty may depend on the further condition that no significant substantial moral or morally relevant reasons against such an enhancement could be adduced. The TMS treatment should not be disproportionally financially burdensome to the legal system, for instance, nor should it create inequalities or unfairness in the legal procedure. If all of these conditions would apply, a moral duty might rightfully be said to exist even without previous agreements, promises or consent.

An obligation would then refer to a responsibility that a person has on the basis of a prior agreement, promise or regulatory framework, such as the law. For example, eyewitnesses in criminal procedures could be legally obliged to undergo TMS treatment because this would improve relevant memories, thus increasing the accuracy of the evidence used, provided that a regulatory arrangement exists occasioning the obligation. For the purpose of explaining the differences between duties and obligations it is not necessary to specify the conditions and circumstances under which such an obligation could exist, whether with or without consent, for instance. (See Klaming, Vedder 2009 for further elaboration.) Of course, obligations and duties can overlap. But they need not do so. An obligation to enhance with TMS may be supported indirectly by moral reasons making the TMS enhancement just morally acceptable, permissible or maybe even morally ideal and therefore supererogatory, without amounting to a moral duty as such. The treatment, however, may equally be supported by non-moral reasons or maybe even morally questionable reasons, e.g. in case of an obligation to enhance oneself on the basis of a regulatory arrangement issued by an illegitimate authority or on the basis of an agreement to which one has committed oneself involuntarily. Whether an obligation to enhance exists or not, does not necessarily depend on there being good moral grounds for the enhancement. In the latter case we could use the expression "moral obligations" or duties.

\section{Who and whom?}


With regard to human enhancement, the enhancer and the enhanced can be but need not be necessarily the same. Enhanced are clearly those on whom forms of enhancement are performed. Perhaps their offspring should be included among the enhanced as well insofar as they manifest the effects intended with the enhancement of their progenitors. Who should be considered an enhancer is a more complicated issue. For purposes of clarification we might want to distinguish operators, such as doctors, nurses, engineers, providers, in brief all who actually perform the treatment, from controllers, i.e., those who take the initiative and decide about applying the specific enhancement. The persons actually performing the treatment by for instance providing a drug or administering the machinery, can be but are not necessarily the same as the persons who decide about applying the enhancement. In the case of the use of TMS for the purpose of witness memory enhancement, the eyewitnesses would be the enhanced. The enhancers would be a legal authority (as controller) and the administrators of the machinery and the magnetic coils (as operators). In case of cognitive enhancement through a simple drug, e.g. Ritalin or a beta blocker for the purpose of mental focus, enhanced and enhancer, both as controller and operator, may be one and the same person.

An obligation to enhance might be addressed to people who, because of that obligation, enhance themselves with or without the help of others. It might however also be addressed to enhancers in the sense of those who demand and enable the enhancement (controllers) or those who perform the enhancement (operators) but who are not being enhanced themselves. In the case of genetic enhancement things might sometimes be more complicated. People might themselves undergo treatment in order to enhance their possible future offspring. Regarding an obligation to enhance, most people will probably primarily think of cases where persons are addressed who themselves undergo enhancement, either provided also by themselves or by professionals. Except for cases in which people undergo genetic enhancement for the benefit of offspring, it might therefore be more to the point to refer to the obligation of the persons who are subjected to enhancing treatment as an obligation to be enhanced rather than an obligation to enhance. This may also help to keep in mind that the existence of an obligation for the person who is (to be) enhanced can create an entitlement or a legitimization for controllers or operators to actually perform the enhancing treatment on the person involved. Again, of course for the moral qualification of such an enhancement and the obligation and entitlement involved, the specific circumstances and conditions, e.g. whether with or without consent, would matter; for a clarification of the relevance of the controllers and operators positions they need not be taken into consideration. For the possibility of an obligation to enhance ever actually to occur, it might be appropriate, therefore, also to consider the particular (moral or legal) positions of the controllers and operators. Fulfilling an obligation to enhance may be far from simple, as it can involve easily three different parties: the enhanced, the controllers, and the operators of the enhancement.

\section{What and for what purpose?}

For the possibility of an obligation to enhance in the sense of a moral duty to enhance, rather than for that obligation as a responsibility on the basis of a prior agreement, promise or regulatory arrangement, important issues of course are: what kind of enhancement is involved and to what end is it applied? As Ruth Chadwick has noted concerning the debate on human 
enhancement: "[T]he important issue is not the distinction between therapy and enhancement but the extent to which enhancement counts as an improvement, which will be dependent upon context and purposes" (Chadwick 2008, 36). Chadwick does not think it is impossible to reach agreements about what is to count as improvement, but she is nonetheless of the opinion that obtaining such agreements will be extremely difficult.

Would moral enhancement - the improvement of cognitive, emotional and physical capacities in order to raise moral sensitivity and abilities for moral reasoning, understanding, wisdom, and persistence, in brief: a person's capacities to act morally right - be a natural candidate for such an agreement? Saliently, two important advocates of enhancement, i.e., John Harris and Julian Savulescu seem to agree about the desirability of enhancement, but to disagree about the types of capacities exactly to be enhanced. Savulescu advocates the enhancement of motivational capabilities whereas Harris rather would prefer enhancement of cognitive capacities in the first place, since he deems these to be more basic than the motivational ones (Harris and Savulescu 2015, 10-14). Beck (2015) may be right in suggesting that controversies on moral enhancement in the end boil down to disagreements about morality in general.

But is actual and complete agreement in these matters really necessary? For many moral claims that are broadly considered to be justified, such actual complete agreements probably cannot be proven to exist. Postulating hypothetical agreement under conditions of rationality and impartiality may be a more solid argument to rely on. Roduit, Heilinger and Baumann (2015) introduced a model that can function as a basis for such an argument. They strongly suggest to use Nussbaum's capabilities approach (Nussbaum 2011) as a basis on which a theory of ideal humanity can be built. The latter theory may offer starting points for discussing desirable enhancements: "[I]n a pluralistic society and in different social and historical contexts, we will not find a consensus regarding what an ideal human being ought to be, act like, and look like. We can nonetheless discuss and agree upon some specific human characteristics (perfectionist assumptions) that appear to be essential for such an ideal human in our current societies. These characteristics can then be used as reference points to assess the morality of human enhancements [...].” (Roduit, Heilinger, Baumann 2015, 627)

So, if we would be able to provide a list of moral enhancements on which hypothetically all could agree that they are indeed morally desirable as the composition of the list is based on sound arguments that will convince rational and impartial persons, it might simultaneously be possible that we would end up agreeing on certain forms of enhancement to be morally obligatory. But would such agreements be probable?

Moral enhancement seems to be primarily motivated by the desire to provide for a better world by making human beings decide and act better. In a world inhabited exclusively by utilitarians or consequentialists in a broad sense, agreement on a list of desirable moral enhancements might therefore be possible. The real world, however, is inhabited by people of various kinds of ethical denominations, most of them being probably ethical eclectics. For Kantians, and people who derive their ethical principles from a variety of sources - Kantian ethics included - a better world might be appealing; but even more appealing to them will be the idea that a world in which people freely decide and freely act rightly is better than a world in which they just do so because they are enhanced by others or have first enhanced themselves in order to realize a better world. Kantians and others who include the value of 
autonomy as a starting points in their moral thinking will have trouble in reconciling the inherent instrumentalism of moral enhancement and the fact that many forms of moral enhancement are enhancements of others with the ideals of moral autonomy and the dignity that comes with moral autonomy. Even if hypothetical agreement on morally desirable forms of moral enhancement is conceivable, it is clear that severe basic problems concerning moral autonomy and moral enhancement will have to be clarified and solved.

\section{Conclusion}

Obligations to enhance can exist in the presence and in the absence of good moral reasons for them. Obligations are based on preceding promises, agreements or regulatory arrangements; they do not necessarily coincide with moral duties. The existence of such obligations therefore need not be morally desirable. If obligation and duty are considered as synonyms, the enhancement involved must be morally desirable in some respect. Since enhancers and enhanced can, but need not coincide, advertency is appropriate regarding the question who exactly is addressed by an obligation or a duty to enhance: the person on whom the enhancing treatment is performed, or the controller or the operator of the enhancement? Especially, the position of the operator is easily overlooked. Finally, the exact functionality of the specific enhancement, is all-important, not only for the acceptability of a specific form of enhancement, but also for its chances of success for becoming a duty or morally obligatory. Moral enhancement is a questionable candidate for becoming morally obligatory, as it seems difficult to reconcile its inherent instrumentalism with the ideals of moral autonomy and dignity, cherished amongst others in the Kantian moral outlook. This does not mean that moral obligations of moral enhancement are impossible, as it may after all be possible to obtain theoretical coherence and consistency concerning moral enhancement and moral autonomy. It does certainly not mean that non-moral obligations of moral enhancement or forms of enhancement that can also function as moral enhancements are impossible, since there might be non-moral reasons for imposing obligations for moral enhancement.

\section{References}

Beck B (2015) Conceptual and practical problems of moral enhancement. Bioethics 29, 4 : $233-240$

Chadwick R (2008) Therapy, Enhancement and Improvement. In: Gordijn B and Chadwick, R (eds), Medical Enhancement and Posthumanity. Springer Science + Business Media

Harris J, Savulescu J (2015) How moral is (moral) enhancement? A debate about moral enhancement. Cambridge Quarterly of Healthcare Ethics 24: 8-22

Klaming L, Vedder A (2009) Brushing Up Our Memories. Can We Use Neurotechnologies to Improve Eyewitness Memory? Law, Innovation and Technology 1, 2: 203-221 
Nussbaum M (2011) Creating Capabilities: The Human Development Approach. Harvard University Press, Cambridge, MA

Roduit J, Heilinger J-C, Baumann, H (2015) Ideas of Perfection and the Ethics of Human Enhancement. Bioethics 29, 9: 622-630

Vedder A, Klaming L (2010) Human Enhancement for the Common Good - Using Neurotechnologies to Improve Eyewitness Memory. AJOB Neuroscience 1, 3: 22-33 